\title{
Attributable, Legible, Contemporaneous, Original, Accurate Plus
}

National Cancer Institute

\section{Source}

National Cancer Institute. Attributable, Legible, Contemporaneous, Original, Accurate

Plus. NCI Thesaurus. Code C156622.

A modified guide to the fundamental elements of data integrity originally described by the US Food and Drug Administration; this acronym stands for attributable, legible, contemporaneous, original, and accurate, as well as the additional elements of complete, consistent, enduring, and available. 